\title{
REDUCTION OF ACUTELY SLIPPED UPPER FEMORAL EPIPHYSIS
}

\author{
Brian H. Casey, Henry W. Hamilton and Walter P. Bobechko, Toronto, Canada
}

From the Hospital for Sick Children, Toronto

Acute slip of the upper femoral epiphysis is uncommon and differs from the more common chronic slip in its clinical presentation. Fahey and O'Brien (1965) defined an acute slip as "characterised by onset of severe pain less than three weeks prior to treatment, . . . and frequently, inability to bear weight".

Few papers deal specifically with the problem. Although it is recognised that closed reduction is possible in an acute slip, the risks involved, the method of reduction and the means used to immobilise the epiphysis have not been established. Fahey and O'Brien (1965) recommended early gentle manipulation under general anaesthesia and maintenance of the reduction by two or three partly threaded pins. Nine of their ten patients were treated in this way. Satisfactory reduction was achieved and good results obtained without evidence of avascular necrosis. Schein (1967) recommended early reduction by skeletal traction with medial rotation, followed by internal fixation with threaded pins at ten days to three weeks. Only one of the eleven patients described was treated by this method, the result being good. Three of the four patients treated by closed manipulation and internal fixation suffered avascular necrosis.

Avascular necrosis of the femoral head is the commonest cause of a poor result in the treatment of slipped upper femoral epiphysis (Hall 1957). The reduction of the acutely slipped femoral head without iatrogenic complication is the subject of this paper.

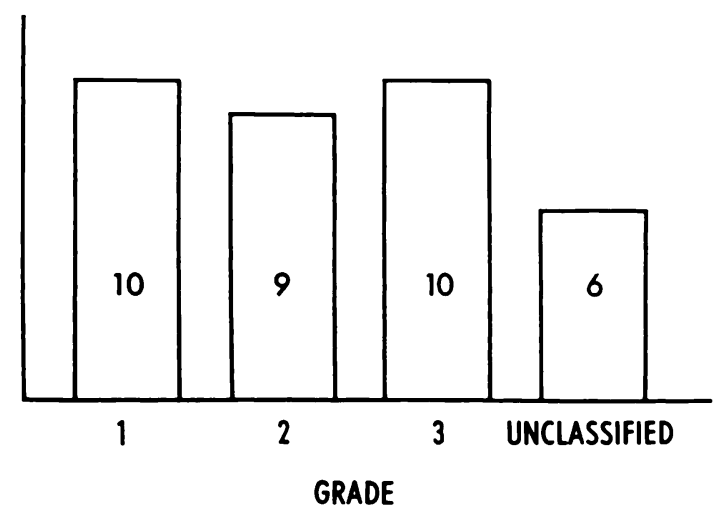

FIG. 1

Classification of patients by degree of slip shown on initial radiographs.

\section{CLINICAL MATERIAL}

Of 122 children with 161 slipped upper femoral epiphyses treated at the Hospital for Sick Children, Toronto, from 1950 to 1969, thirty-four presented with thirty-five acute slips. (One child had an acute slip on one side, followed a year later by an acute slip on the other side.) There were twenty-two boys and twelve girls. The average age of the boys was thirteen years and of the girls eleven years.

Mild prodromal symptoms consisting of hip, thigh or knee pain or a limp had been present in twenty-seven cases. These symptoms commonly had been present for one week to three months, but the range was two days to one year. The onset of the acute symptoms followed 
trauma in most cases: eight patients sustained sports injuries, five fell from bicycles and nineteen suffered other falls. In three cases there was no history of injury; for example, one boy had a sudden onset of pain in the hip while running and was then unable to walk.

After the onset of acute symptoms sixteen patients were unable to walk, and ten walked with difficulty and a limp. In the remaining cases the records did not indicate walking ability. Eighteen patients were admitted within one day of the onset of the acute pain, eight within two to seven days, and seven within one to two weeks.

We reviewed the initial radiographs taken in two planes and classified the slip according to the degree of displacement of the head of the femur relative to the neck: Grade 1, less than 25 per cent; Grade 2, 26 to 50 per cent; and Grade 3, more than 50 per cent. The patients were classified according to their greatest degree of slip; in most cases the degree of slip
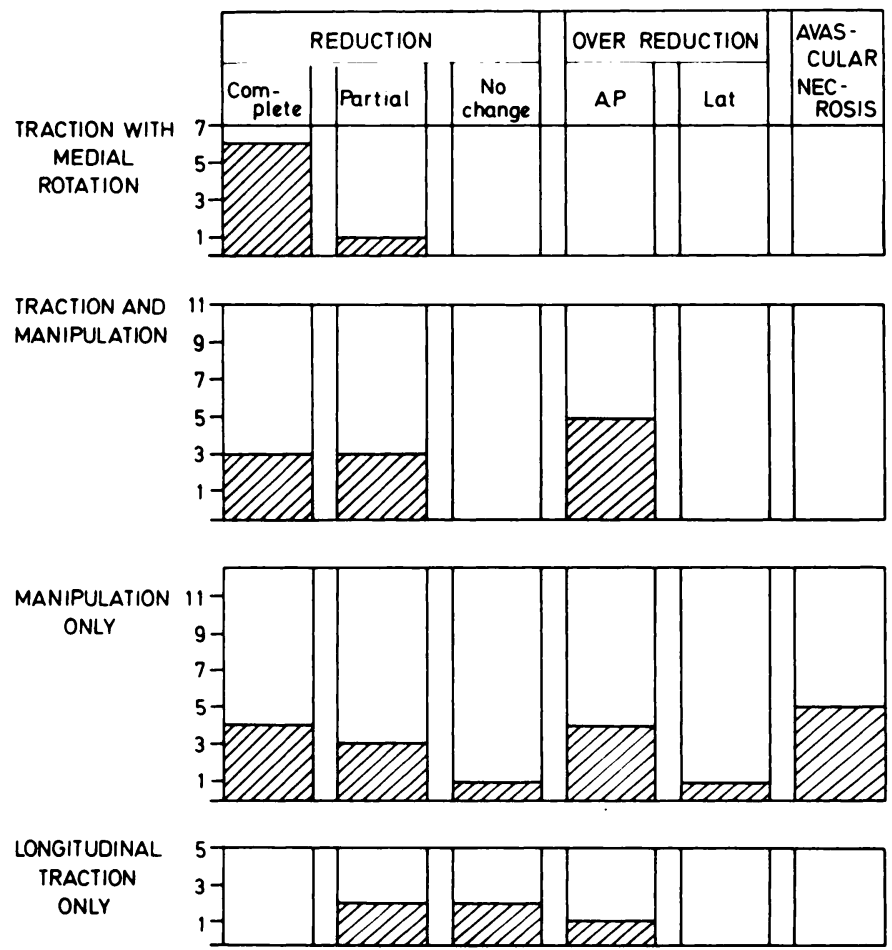

Fig. 2

Results with various methods of reduction.

observed in the lateral view exceeded that in the antero-posterior view. Figure 1 shows the distribution of the various grades of slip in our patients. The hip pain, lateral rotation deformity and limited range of movement made it difficult to obtain true antero-posterior and lateral radiographs, and six patients could not be classified.

Evidence of some degree of neck remodelling, and thus of pre-existing chronic slip, was present in seventeen cases, doubtful in six cases, and absent in six cases.

All the patients were reviewed or had adequate follow-up records and radiographs at least two years after the initial treatment.

\section{MANAGEMENT}

Over the twenty-year period of this review the several staff surgeons in charge of the cases had used various methods of treatment. Traction in bed with medial rotation, and manipulation under general anaesthesia were used alone or in combination to reduce the displaced epiphysis. 
In cases with the least slip longitudinal traction was used to make the patients comfortable before operation.

In most cases the epiphysis was immobilised by internal fixation. In the early part of the period large standard Smith-Petersen nails were used, but later, specially made thin sharp Thornton nails were preferred. In one case Knowles pins were used and in one other, subtrochanteric osteotomy was done at the same time and fixed internally with a plate attached to a thin nail. Two patients were immobilised in hip spicas without internal fixation.

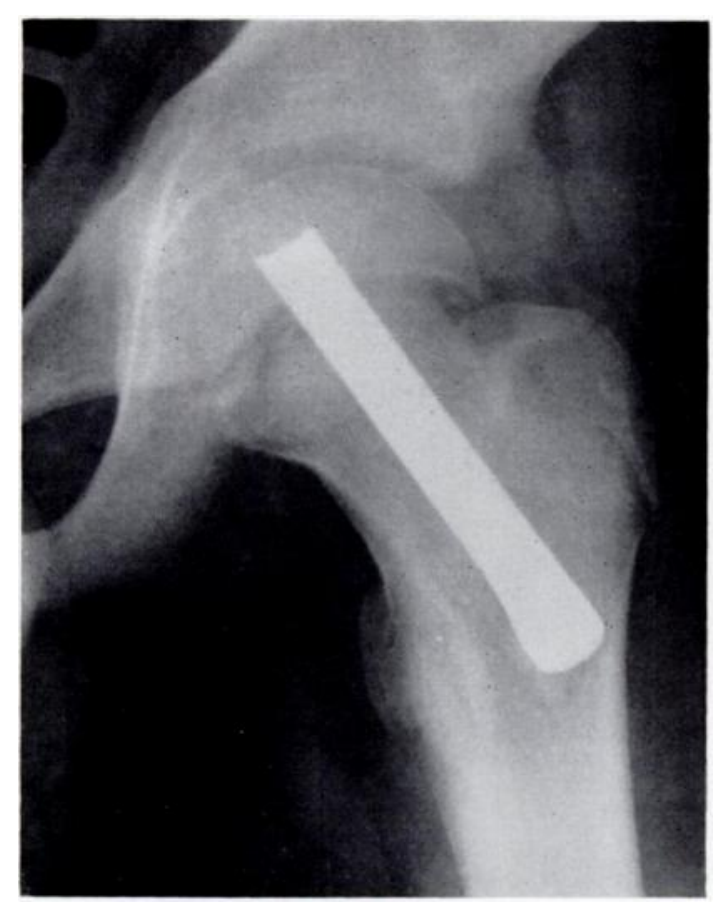

FIG. 3

Left hip showing over-reduction. (Case 22.)

\section{RESULTS}

Reduction of displacement-Figure 2 outlines the results of the various methods of reduction. Traction with medial rotation, when used alone in seven cases, completely reduced six displacements and partly reduced one.

When traction with medial rotation was followed by manipulation under general anaesthesia in eleven cases, three slips were completely reduced, three partly reduced and five over-reduced.

Manipulation under general anaesthesia used alone in twelve cases completely reduced four slips, partly reduced three, failed to change one, and over-reduced four. Over-reduction (as in Figure 3) thus occurred in nine of the twenty-three cases when manipulation under general anaesthesia was used.

With longitudinal traction alone in five patients with very slight displacement, two slips were partly reduced, two were unchanged, and one was over-reduced.

In the twelve patients treated by manipulation alone avascular necrosis occurred in five cases and was associated with over-reduction in three. Figures 4 to 12 illustrate a case of avascular necrosis.

Immobilisation of the epiphysis-Avascular necrosis complicated one of the fourteen cases in which a large nail had been used, and three of the eighteen cases in which a thin sharp nail

VOL. 54 B, NO. 4, NOVEMBER 1972 
had been used. Avascular necrosis also occurred in the case in which Knowles pins had been used. The cases treated by hip spicas were uncomplicated.

Degree of slip-Avascular necrosis complicated one of the ten hips with Grade 1 slips, two of the nine hips with Grade 2 slips, one of the ten hips with Grade 3 slips and one of the six hips with unclassified slip. Details of the five cases in which avascular necrosis was recognised are listed in Table I.

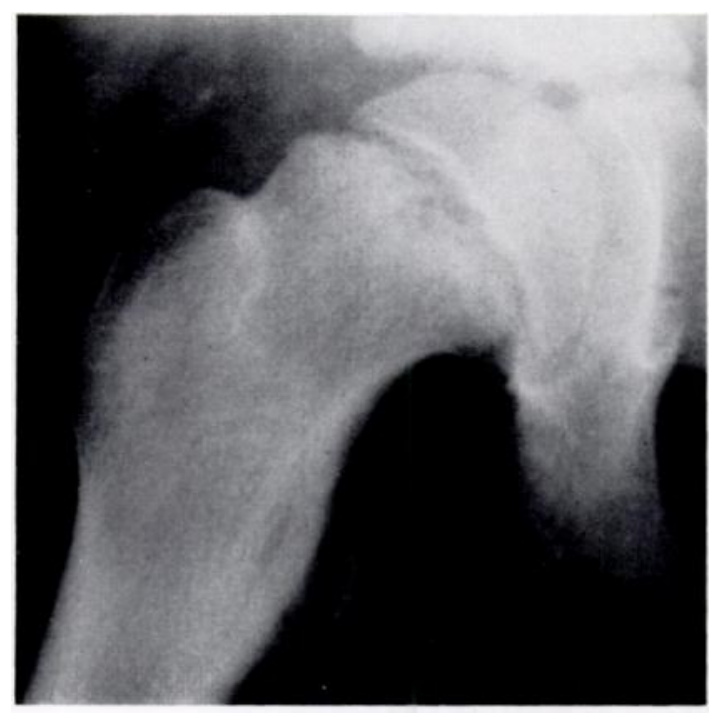

FIG. 4

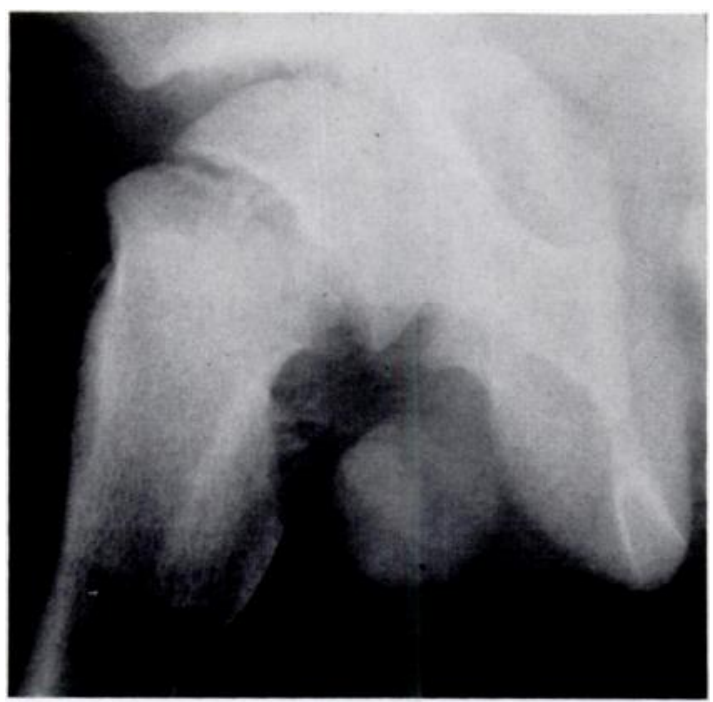

Fig. 6

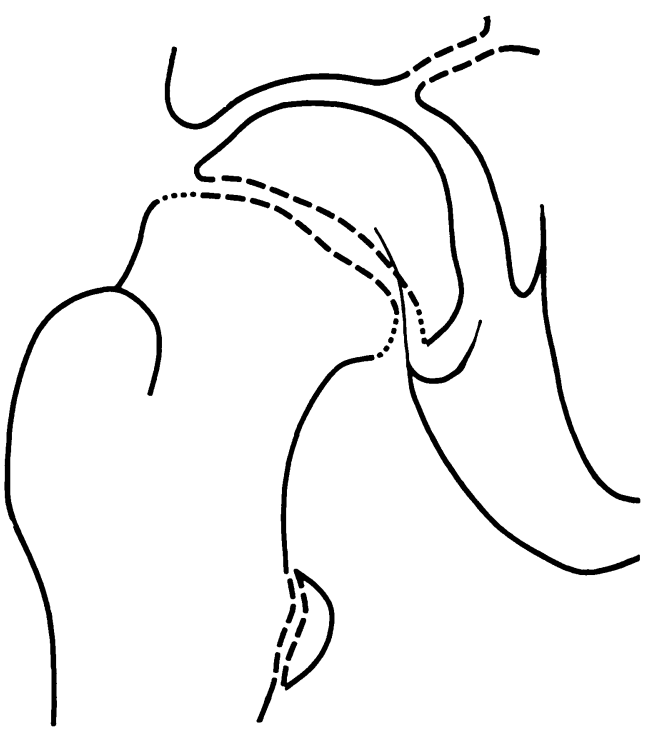

FIG. 5

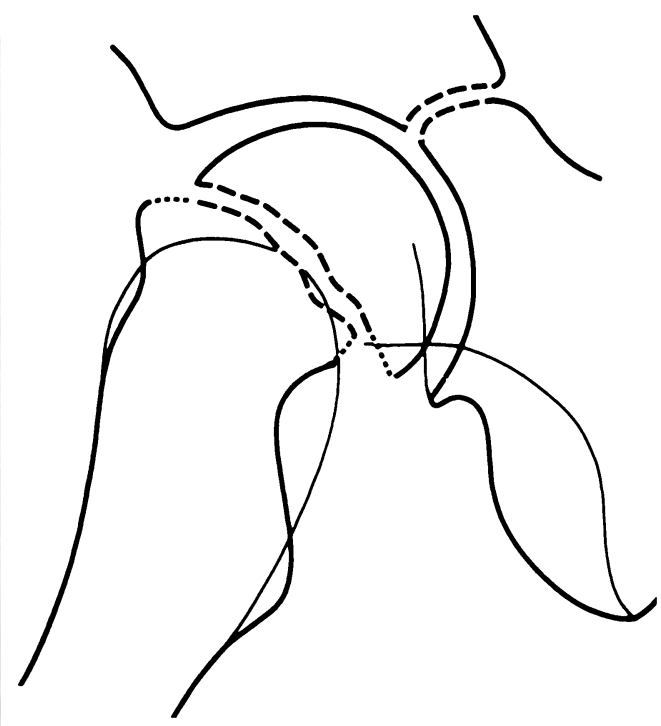

Fig. 7

Antero-posterior and lateral radiographs of right hip showing Grade 1 slip. (Case 6.)

\section{DISCUSSION}

Our findings suggest that traction with medial rotation is an effective and safe method of reducing acutely slipped upper femoral epiphyses, whereas manipulation under general anaesthesia carries a significant risk of avascular necrosis. The fact that avascular necrosis 
did not complicate those displacements manipulated after preliminary traction suggests that the timing of the manipulation may be important. Table II shows that four of the five cases of avascular necrosis followed manipulation undertaken within a week of the acute episode, when an inflammatory effusion might have jeopardised a tenuous blood supply.

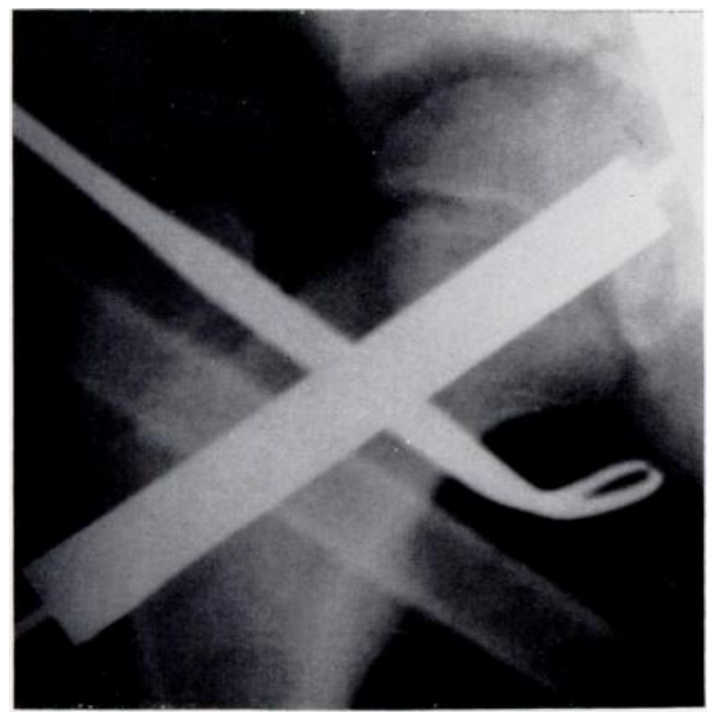

FIG. 8

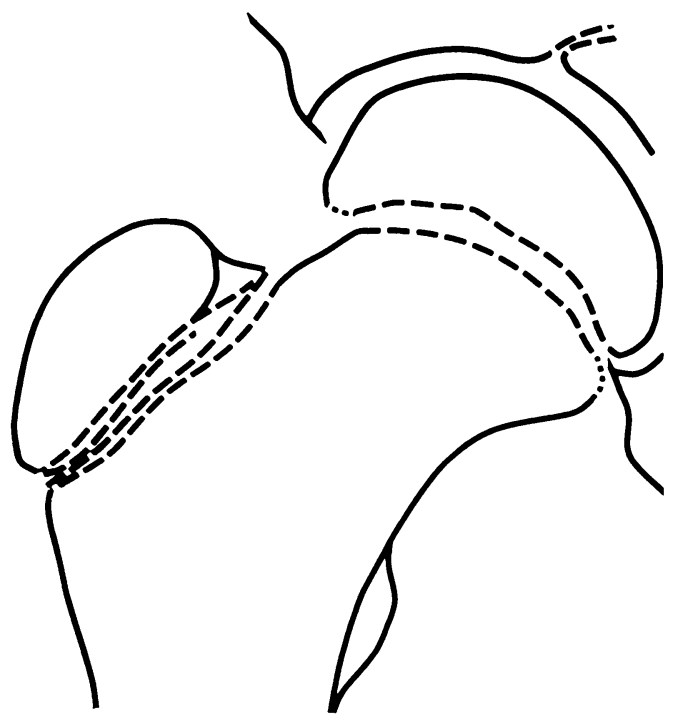

FIG. 9

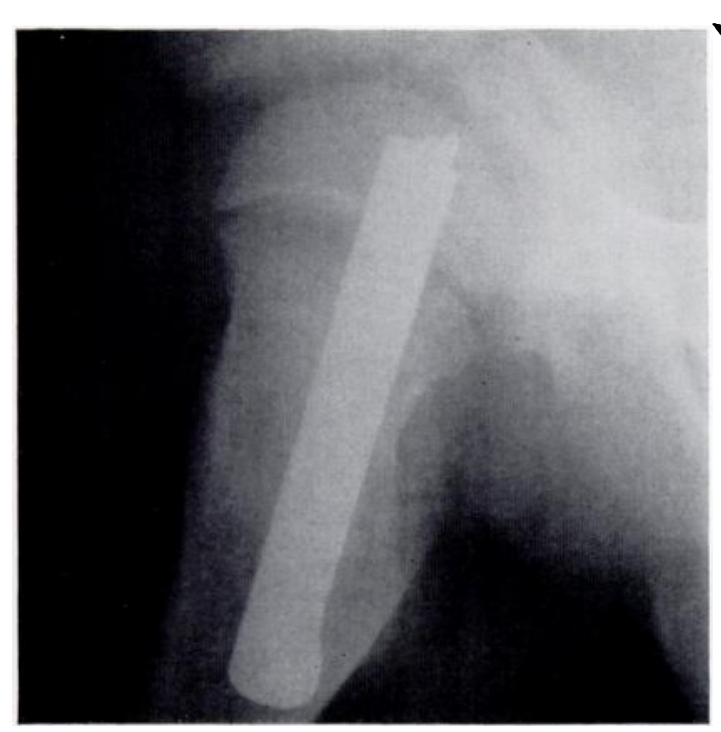

Fig. 10

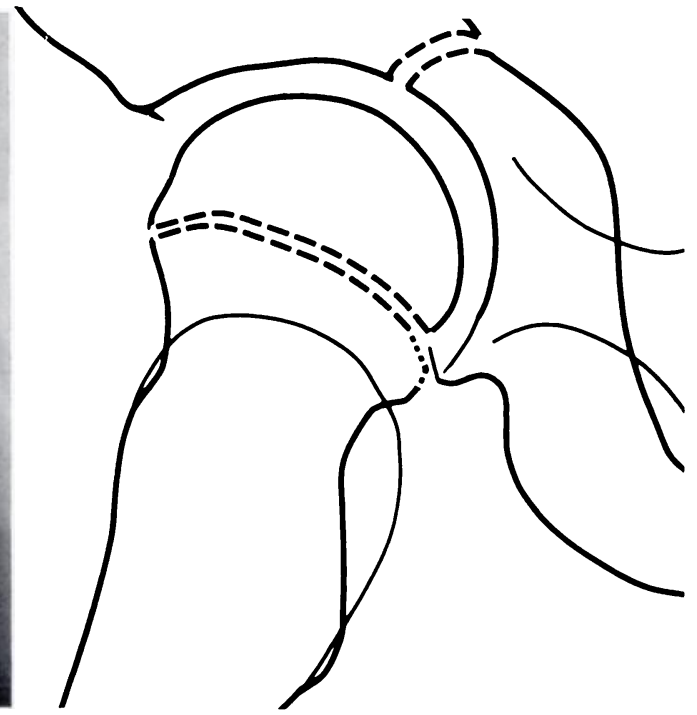

FIG. 11

Radiographs after operation on right hip, showing internal fixation of epiphysis with a large nail, in a position of over-reduction. (Case 6.)

Over a third of the slips manipulated under general anaesthesia were over-reduced. The association of avascular necrosis with over-reduction in three of the five cases may be because the blood vessels on the inferior and posterior aspects of the femoral neck, the ones most likely to survive the initial slip (Dunn 1964, Crock 1967), are traumatised by sudden manipulative over-reduction. We therefore doubt the safety of even the gentle manipulation 
advocated by Hall (1957) and Fairbank (1969). We support the more cautious approach of Schein (1967).

We drew no conclusions as to the best method of immobilising the epiphysis. However, when a subtrochanteric osteotomy is to be undertaken at the same time, it can be conveniently secured by adding a plate to a Thornton nail.

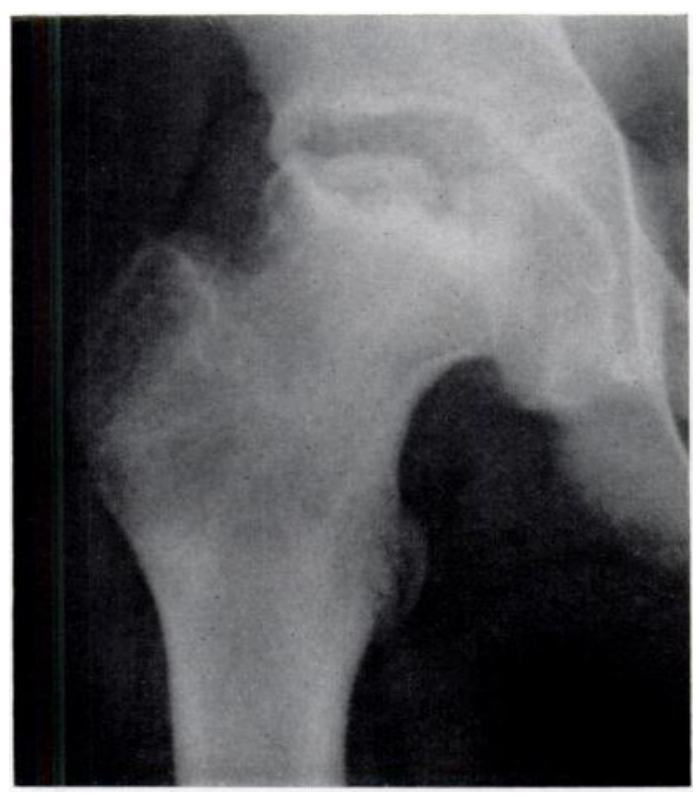

FIG. 12

Antero-posterior view of the right hip seventeen months after operation, showing avascular necrosis of the whole head with collapse. (Case 6.)

With regard to the degree of slip, severe initial displacement of the epiphysis does not indicate that avascular necrosis will necessarily follow.

TABLE I

Five Cases of Avascular Necrosis

\begin{tabular}{|c|c|c|c|c|c|}
\hline \multirow{2}{*}{$\begin{array}{c}\text { Case } \\
\text { number }\end{array}$} & \multirow{2}{*}{$\begin{array}{l}\text { Initial } \\
\text { grading }\end{array}$} & \multicolumn{2}{|c|}{ Position after manipulation } & \multirow{2}{*}{$\begin{array}{l}\text { Method of } \\
\text { internal fixation }\end{array}$} & \multirow{2}{*}{$\begin{array}{l}\text { Avascular } \\
\text { necrosis }\end{array}$} \\
\hline & & $\mathbf{A P}$ & Lateral & & \\
\hline 6 & 1 & Over-reduced & Over-reduced & Large Smith-Petersen nail & Complete \\
\hline 17 & 2 & Over-reduced & Reduced & Thin, sharp Thornton nail & Complete \\
\hline 18 & 2 & Over-reduced & Reduced & Knowles pins & Complete \\
\hline 20 & 3 & Reduced & Grade 1 & Thin, sharp Thornton nail & Complete \\
\hline 35 & $\begin{array}{c}\text { Not } \\
\text { classified }\end{array}$ & Reduced & Grade 2 & Thin, sharp Thornton nail & Partial \\
\hline
\end{tabular}

Recommendations-Acute slip of the upper femoral epiphysis, presenting within two to three weeks of the onset of severe pain, should be treated as an emergency by skin traction with medial rotation. After three or four days, whether or not reduction has been achieved, the 
epiphysis should be pinned in situ. If the reduction of the epiphysis is not acceptable subtrochanteric osteotomy (Gibson 1966) should be done at the same time, the epiphysis being correctly aligned to the femoral shaft and secured by adding a plate to the Thornton nail. We believe that by following this routine, iatrogenic avascular necrosis can be avoided and good results obtained.

TABLE II

Timing of Manipulation

\begin{tabular}{|c|c|c|c|c|}
\hline $\begin{array}{c}\text { Case } \\
\text { number }\end{array}$ & $\begin{array}{l}\text { From acute } \\
\text { onset to } \\
\text { manipulation } \\
\text { (days) }\end{array}$ & Method of reduction & $\begin{array}{l}\text { Over- } \\
\text { reduction }\end{array}$ & $\begin{array}{c}\text { Avascular } \\
\text { necrosis }\end{array}$ \\
\hline 12 & 1 & Manipulation only & & \\
\hline 18 & 1 & Manipulation only & $\therefore$ & Total \\
\hline 35 & 1 & Manipulation only & & Partial \\
\hline 31 & 2 & Manipulation only & & \\
\hline 34 & 3 & Manipulation only & & \\
\hline 5 & 4 & Manipulation only & $\therefore$ & \\
\hline 17 & 4 & Manipulation only & + & Total \\
\hline 30 & 4 & Manipulation only & & \\
\hline 15 & 5 & Traction and manipulation & & \\
\hline 24 & 5 & Traction and manipulation & & \\
\hline 6 & 6 & Manipulation only & it & Total \\
\hline 8 & 6 & Traction and manipulation & & \\
\hline 25 & 6 & Traction and manipulation & $\because$ & \\
\hline 33 & 7 & Manipulation only & & \\
\hline 13 & 8 & Traction and manipulation & & \\
\hline 11 & 10 & Traction and manipulation & & \\
\hline 9 & 12 & Traction and manipulation & $\because-$ & \\
\hline 32 & 12 & Manipulation only & & \\
\hline 14 & 12 & Traction and manipulation & $\therefore$ & \\
\hline 20 & 16 & Manipulation only & & Total \\
\hline 22 & 21 & Traction and manipulation & + & \\
\hline 19 & 22 & Traction and manipulation & & \\
\hline 16 & 34 & Traction and manipulation & $\therefore$ & \\
\hline
\end{tabular}

\section{SUMMARY}

1. The results of thirty-five acutely slipped upper femoral epiphyses, treated from 1950 to 1969, are presented. Avascular necrosis of the femoral head occurred in five cases.

2. Skin traction with medial rotation, followed in three to four days by internal fixation, without further manipulation, is recommended so that this iatrogenic complication may be avoided.

VOL. 54 B, NO. 4, NOVEMBER 1972 
We are indebted to the surgeons of the Hospital for Sick Children, Toronto, for allowing us to include their cases in this review, and to the Departments of Visual Education and Medical Publications for the preparation of this manuscript.

\section{REFERENCES}

Crock, H. V. (1967): Slipping Upper Femoral Epiphysis. In The Blood Supply of the Lower Limb Bones in Man, p. 92. Edinburgh and London: E. \& S. Livingstone Ltd.

Dunn, D. M. (1964): The Treatment of Adolescent Slipping of the Upper Femoral Epiphysis. Journal of Bone and Joint Surgery, 46-B, 621.

Fahey, J. J., and O’Brien, E. T. (1965): Acute Slipped Capital Femoral Epiphysis. Journal of Bone and Joint Surgery, 47-A, 1105.

Fairbank, T. J. (1969): Manipulative Reduction in Slipped Upper Femoral Epiphysis. Journal of Bone and Joint Surgery, 51-B, 252.

Gibson, D. A. (1966): Slipped Upper Femoral Epiphyses: Review of the Late Results of Subtrochanteric Osteotomy. Canadian Journal of Surgery, 9, 153.

Hall, J. E. (1957): The Results of Treatment of Slipped Femoral Epiphysis. Journal of Bone and Joint Surgery, 39-B, 659.

Schein, A. J. (1967): Acute Severe Slipped Capital Femoral Epiphysis. Clinical Orthopaedics and Related Research, 51, 151. 